\title{
Niños del cielo. Análisis psicoestético y socioeducativo de un filme iraní
}

\author{
Eduardo Llanos Melussa
}

Universidad Diego Portales, Santiago, Chile. Email: eduardo.llanos@udp.cl

Resumen: Se propone un análisis de la película Niños del cielo, dirigida por Majid Majidi. Se examinan seis dimensiones del filme (interpersonal, intrapersonal, transpersonal, ideológica, simbólica y estética), y los comentarios proponen seis niveles posibles de exploración y comprensión (descriptivo, inferencial, interpretativo, valorativo, introspectivo y creativo). Aunque el ejercicio sigue un modelo propio, en su elaboración conjuga al menos cuatro aportes principales: la “Educación por el Arte”, la Enseñanza para la Comprensión, el modelo estructural del intelecto propuesto por J. P. Guilford y el enfoque sociocultural y sociocrítico de la educación.

Palabras clave: apreciación estética, educación por el arte, enseñanza para la comprensión, psicología de la comunicación, enfoque sociocultural.

\section{Children of heaven. A psychoaesthetic and socioeducative analysis about an Iranian film}

\begin{abstract}
It's proposed an analysis about the film Children of Heaven, directed by Majid Majidi. Six dimensions about the film are examined (interpersonal, intrapersonal, transpersonal, ideological, symbolical and aesthetic), and the comments embrace six levels of exploration and understanding (descriptive, inferential, interpretative, appreciative, introspective and creative). Although the drill follows a personal pattern, in its upbringing at least four main contributions are fused: the "Education through Art", The Teaching for Understanding, the structural model of the intellect proposed by J. P. Guilford, and the sociocultural and sociocritical approach on education.

Key words: aesthetic appreciation, education through art, teaching for comprehension, psychology of communication, sociocultural approach.
\end{abstract}

\section{Crianças do ceu. Analise socio e psicoestetico de un filme iraniano}

Resumo: O artigo propõe uma análise do filme Crianças do Céu, dirigido por Majid Majidi. São examinadas seis dimensões do filme (interpessoal, intrapessoal, transpessoal, ideológica, simbólica e estética) e os comentários sugerem seis níveis possíveis de exploração e compreensão (descritiva, inferencial, interpretativa, avaliativa, introspectiva e criativa). Embora o exercício escolha seu 
próprio modelo, na sua preparação combina pelo menos quatro contribuições principais: A "Educação pela Arte"; Ensino para a compreensão; O modelo estrutural do intelectoproposto por JP Guilford; ea abordagem sociocultural e sociocríticoda educação.

Palavras-chave: apreciação estética, educação para arte, ensino para a compreensão, psicologia da comunicação, abordagem sociocultural.

$$
* * *
$$

\section{Introducción}

Como se indicó en el resumen, el presente análisis de Niños del cielo aplica un modelo de apreciación psicocinematográfica que examina la película en seis dimensiones, recorrido que a su vez presupone un orden creciente de niveles de comprensión, desde el más ingenuo hasta el más "profundo", desde la lectura más literal hasta la más autónoma o "libre”. Cruzando las seis dimensiones del análisis con los seis niveles de profundidad del mismo, se obtendría un cuadro de treinta y seis cuadrículas. Por cierto, ese cuadro eventual no constituye una prótesis ni un tour de force, sino más bien una carta de navegación flexible.

En efecto, un largo trabajo docente ha mostrado empíricamente que este mapeo inicial (las seis dimensiones de análisis y los seis niveles de comprensión), cuando es ofrecido flexiblemente y no impuesto como un corsé, orienta a los estudiantes hacia la metacognición y promueve el desarrollo de habilidades transversales. Esto ocurre porque el método propicia la toma de conciencia de las distintas operaciones que confluyen en la comprensión: empezando por la sensopercepción espontánea (más o menos atenta), siguiendo luego con la observación intencional, el razonamiento, el discernimiento, la autognosis y la creatividad).

Comenzaré ofreciendo la ficha técnica de la película, una sinopsis de la historia y una explicación sintética del modelo aplicado. En la parte principal, se sigue el orden ya señalado en el abstract: es decir, para cada uno de los seis planos de análisis (interpersonal, intrapersonal, transpersonal, ideológico, simbólico, estético) se formulan comentarios que empiezan por lo observable, siguen luego por lo inferible, prosiguen por lo interpretable y así sucesivamente. Estos seis niveles se explicitan retrospectivamente en la penúltima parte del artículo, donde se los asocia a las operaciones mentales requeridas en cada caso. Finalmente, se ofrecen algunas reflexiones psico- y socioeducacionales.

\section{Ficha técnica y sinopsis}

Título: Niños del cielo (también traducida como Niños del paraíso). Director: Majid Majidi (Teherán, 1959).

País: Irán. 
Año: 1997.

Género: Drama.

Duración: 87 minutos.

Idioma: Iraní (persa).

\section{Sinopsis}

La película está ambientada en el Irán contemporáneo, específicamente en Teherán. Comienza con un primer plano a unas manos masculinas que se esmeran en remendar un zapato rosado de niña. Alí, un niño de unos ocho años, recibe el par de zapatos recién remendados y cancela el trabajo; enseguida pasa a comprar pan y, por último, va a la tienda de frutas y verduras, donde consigue que le fíen unas papas de segunda selección. Como debe escogerlas una por una, deja momentáneamente los zapatos entre unos cajones, y en ese ínterin un menesteroso carretonero se los lleva. Cuando Alí termina su compra y se apresta a irse, busca en vano los calzados; insiste en la búsqueda y sin querer provoca la caída de algunas frutas, hecho que irrita al verdulero. Pese a sus angustiosos esfuerzos, debe volver a casa sin los zapatos de su pequeña hermana Zahra, quien esperaba seguir usando esos zapatos remendados. Al escuchar que él los perdió fortuitamente, ella se muestra contrariada, ya que no tendrá cómo acudir a la escuela.

A partir de entonces el dramatismo se intensifica. Alí convence a Zahra de no contar el asunto al padre, pues éste tiene muchas preocupaciones: aparte de la precariedad económica (subsisten con trabajos esporádicos del padre y gracias a que les fían algunos alimentos), viven en un espacio muy pequeño y adeudan el arriendo; además, la madre está casi postrada por una enfermedad y recientemente ha dado a luz a un nuevo hermanito. Pese a estas preocupaciones, el padre mantiene su esperanza y su fe, y colabora gratuitamente con algunos quehaceres en la mezquita.

Alí y Zahra mantienen en secreto la pérdida de los zapatos y, aprovechando que asisten a la escuela en jornadas diferentes, deciden compartir las zapatillas de Alí. Zahra, cuya jornada es matinal, debe asistir calzando las zapatillas del hermano y correr de vuelta apenas termine la última clase; a su vez, Alí debe esperarla a medio camino en un callejón, cambiarse las zapatillas y partir corriendo a la escuela. Dado que el tiempo para este intercambio es muy breve y la distancia es considerable, Alí se esfuerza en correr a la mayor velocidad posible; aún así, a menudo llega atrasado y es reconvenido severamente por el inspector, quien no cree sus explicaciones y amenaza con suspenderlo en caso de llegar tarde otra vez. Y como Alí vuelve a atrasarse, el inspector decide suspenderlo de clases y exigir que acudan sus padres para discutir el asunto. Alí se salva sólo gracias a que su maestro intercede en su favor aduciendo que Alíes un buen estudiante.

Paralelamente, la pobre Zahra soporta con estoicismo la incomodidad y la vergüenza de acudir a clases calzando las zapatillas de su hermano -bastante usadas, por lo demás-, y continúa solidarizando lealmente con 
su hermano en el ocultamiento del extravío de los zapatos. Incluso un día descubre que una compañera de la escuela está usando sus viejos zapatos. Se trata de la hija o la nieta de una familia muy pobre, acaso más necesitada que ellos, de modo que ambos hermanos renuncian a cualquier intento de recuperarlos.

En otro pasaje vemos a Alí acompañando a su padre a un barrio acomodado para ganar algún dinero con trabajos ocasionales. Aunque en una mansión les pagan bien por jardinear, a la bicicleta se le cortan los frenos en el regreso. Padre e hijo terminan así estrellándose y la bicicleta queda averiada.

Cuando ya parece no haber solución para estos atribulados y abnegados personajes, surge una tenue luz de esperanza: llega a la escuela una convocatoria para una corrida interescolar, cuyo tercer premio es precisamente un par de zapatillas. Alí se entera a destiempo, cuando ya estaban cerradas las inscripciones; entonces suplica al entrenador que lo inscriba, prometiendo ganar la carrera. Aunque en principio lo rehúsa, el entrenador se allana a inscribirlo, no sin antes evaluar la capacidad del niño.

La competencia se desarrolla en un parque junto a una laguna o tranque. Todo sugiere que Alí está solo y en un contexto socioeconómico distinto: céspedes bien cuidados y extensos, niños vestidos con zapatillas y buzos deportivos especiales, padres que han traído en vehículos propios a sus hijos y los alientan. Con gran denuedo, Alí empieza a ubicarse en el grupo de avanzada. Se esfuerza por mantenerse en el tercer puesto; sin embargo, un empujón lo hace caer y debe reincorporarse. Da alcance nuevamente al grupo de los seis mejores, que van enfilando casi juntos a la meta. Alí hace un último esfuerzo para asegurar su tercer lugar (que le permitiría ganar las zapatillas como premio), pero la llegada es tan estrecha que no puede medir bien su velocidad y termina arribando primero. Paradójicamente, aunque esto le significa ser felicitado por su profesor y por el inspector de su escuela e incluso ser fotografiado por los periodistas, Alí entristece, pues no podrá cumplir lo prometido a su hermana.

Así llega a casa con un primer puesto que no lo alegra ni lo enorgullece. Su hermana lo recibe con una mezcla de desilusión y comprensión. Sin embargo, el padre viene llegando y trae en la parrilla de su bicicleta una grata sorpresa para Zahra y Alí.

\section{Seis dimensiones o planos de análisis}

En esta sección se exploran seis dimensiones psicofílmicas: las tres primeras remiten a los personajes (planos interpersonal, intrapersonal y transpersonal), y las tres restantes se abren a aspectos socioculturales y propios del cine (planos ideológico, simbólico y estético). Para una descripción y explicación detallada de estas seis dimensiones, ver Llanos (2002); para una aplicación del modelo, véase el análisis de ¿A quién ama Gilbert 
Grape? (Ibid, 2010).

\section{Plano interpersonal}

En esta historia resultan particularmente nítidos los distintos niveles de organización: la díada fraterna, la familia como un todo y el sistema sociocultural. A continuación ofrezco seis comentarios hilvanados de forma ascendente, con arreglo a esa jerarquía implícita.

1.1.- Lealtad y fraternidad.-De entrada, asombra la lealtad que preside la relación entre Alí y Zahra, que es más intensa y profunda que lo esperable a partir del simple lazo sanguíneo. Escrutando ese vínculo, se puede inferir que descansa sobre un acuerdo básico: para ambos es prioritario evitar que el padre tenga un nuevo motivo de preocupación. Semejante cuidado no parece deberse sólo al temor de un posible castigo paterno; más bien cabe interpretarlo como una preocupación ética, pues todo indica que los hijos se ponen en el lugar del padre y comprenden que éste es todo lo buen padre y esposo que con sus recursos puede ser, de modo que sería injusto recargarlo más.

1.2.- Cooperación y honestidad.- La lealtad que rige el subsistema de los hermanos nos aporta una primera pista para elevar la mirada hacia el nivel superior: el sistema familiar como un todo. Allí imperan la colaboración y una sana resignación. Por cierto, la precariedad material no puede menos que afectar a personas tan sensibles; sin embargo, diversos indicios sugieren que las buenas intenciones sustentan todos los vínculos. Se puede interpretar que cada cual confía en que el otro está haciendo también su mejor esfuerzo, y de ese modo afrontan estrecheces y adversidades.

1.3.-Estructura y funcionamiento de la familia.-Pese a su sencillez, esta pequeña familia tiene cierta complejidad estructural. Para empezar, se notan claramente tres subsistemas familiares de carácter diádico: [1ํㄱ los hermanos, cuya fuerte unión ya se ha destacado; $\left[2^{\circ}\right]$ las díadas padre-hijo y madre-hija, ambas claramente organizadas en función del género; $\left[3^{\circ}\right]$ finalmente, los padres, más ocupados en su rol de tales que en su relación de pareja. Por lo mismo, cabe preguntarse si la vida marital de estos padres no sería más rica en caso de contar con mayor holgura (no sólo económica, sino también espacial). Pero si bien la estrechez reduce casi a cero los espacios personales y los de intimidad, también favorece la cohesión familiar.

Por otro lado, a primera vista cabría pensar que en este hogar prevalece el autoritarismo; sin embargo, se trata más bien de severidad. En todo caso, el padre es muy estricto con Alí y más cariñoso con Zahra, diferencia de trato que parece deberse no sólo a la edad de los hijos, sino también al género. En este sentido, hay ciertos indicios de que en el macrosistema sociocultural imperan normas muy similares: a los hombres se les exige que sean proveedores, mientras de las mujeres se espera que sean hacendosas y abnegadas. Retomaré este punto en el plano ideológico. 
1.4.- Los vínculos en los sectores acomodados.- Un aspecto contrastante es la soledad del niño rico, que no tenía con quien jugar. En cierto modo, su abuelo tuvo que “arrendar” la amistad de Alí para entretener al nieto. Esto se correlaciona con la soledad del barrio acomodado, en cuyas limpias y amplias calles no circulan personas. Finalmente, si se toman la indumentaria y el aspecto como indicadores de nivel socioeconómico, cabe notar que en la carrera los niños más competitivos son precisamente los que parecen provenir de estratos más pudientes; de hecho, uno de ellos da un empujón a Alí y lo hace caer (recordemos que eso gatilla el triunfo involuntario de nuestro protagonista).

1.5.-Los vínculos y el contexto educacional.-Por una suerte de miopía o de prejuicio, es común “explicar” las dinámicas interpersonales principalmente a partir de los rasgos caracteriales de los interactores; sin embargo, el sistema sociocultural también gravita sobre los vínculos e incluso sobre la personalidad. En el caso de esta película, se observa que la educación opera como interfaz entre el individuo y la cultura. Por ejemplo, en la escuela prevalece la normatividad, como se aprecia marcadamente en el inspector y secundariamente en el entrenador; sin embargo, éstos no son arbitrarios, sino estrictos. Se podría contraargumentar aduciendo como excepción al profesor de Alí, quien muestra un trato más personalizado y comprensivo; no obstante, tal trato se debe a los méritos estudiantiles del protagonista-que el docente ha conocido directamente en la sala de clases- antes que a su simple condición de niño. En otras palabras, el sistema educacional premia a sus integrantes en la medida en que se atienen a las normas que los rigen. Y este apoyo social se manifiesta oportunamente: cuando el profesor ve a Alí atribulado por la sanción que le impuso el inspector, intercede justo a tiempo en su favor; asimismo, cuando Alí impetra al entrenador para participar en la carrera, éste termina accediendo; en otro plano, Alí y Zahra deponen su intento de recuperar los zapatos al descubrir cuán precariamente vive la nueva dueña de los zapatos.

1.6.- Interacción, religiosidad y contexto sociocultural.-Otro tanto parece ocurrir en el ámbito religioso: el fervor y la responsabilidad del padre son evidentes, y es en vista de eso que el encargado de la mezquita le presta solidariamente su equipo de jardinería para que se agencie algún dinero haciendo trabajos ocasionales. Así, cabe concluir que en este sistema sociocultural la solidaridad y la cooperación no se prodigan de modo incondicional, sino como respuesta proporcional ante actitudes meritorias, actitudes que precisamente expresan, sostienen y refuerzan el ethos compartido, núcleo último de la identidad cultural y de la cohesión social.

\section{Plano intersubjetivo}

2.1.-Preponderancia del cariño.-Aunque Alí siente culpa por haber perdido los zapatos de su hermana, su actitud no se reduce a ese sentimiento: también lo vemos afligido y compungido por la molestia que involuntariamente provocó, y hay diversos indicios de que siente un auténtico cariño de hermano. No menos genuinos resultan los sentimientos 
de la pequeña Zahra, quien además se encarga de ayudar en la crianza del hermano bebé. Finalmente, aunque adusto, el padre se ve también cariñoso e íntegro.

2.2.-Autoentrampamiento por promesas incompatibles. -Alí sobrelleva una carga de angustia y tensión permanente, como si sintiera el peso de una adultización prematura. En este sentido, resulta muy elocuente un hecho que pasa más bien inadvertido ${ }^{1}$ : Alí promete a su hermana llegar tercero (para así ganar el par de zapatillas), mientras que al entrenador le promete llegar primero (para retribuir así el favor de haberlo incluido en el equipo). Puesto que Alí tiene bastante interiorizado el compromiso, cabe presumir que la incompatibilidad de ambas promesas lo entrampa y lo angustia.

2.3.-Sencillez.-El padre resulta visiblemente superado por la mayor inteligencia del hijo, pero si bien ello le provoca cierta turbación, sigue cumpliendo su rol paterno, pues Alí lo respeta sin ambivalencias. Por su parte, Zahra es tan inteligente y sencilla como su hermano. En suma, cuesta no ver en todo eso el resultado de valores compartidos e interiorizados a través de ejemplos parentales y de un sistema sociocultural cohesivo.

2.4.- Resignación.-En términos generales, se aprecia cierta resignación tanto en Alí como en Zahra, que en todo caso no les impide perseverar en sus propósitos. Por ejemplo, Alí declina las invitaciones de sus amigos para jugar y Zahra entiende que no vale la pena intentar que la compañera le devuelva los zapatos (pues ella no parece culpable de haberlos robado). Por su parte, los padres también presentan cierta resignación, pero no indolencia ni pasividad. Una vez más, todo esto sugiere que estamos ante valores socioculturales.

2.5.- Invisibilidad de las virtudes infantiles.-Cada uno a su turno, el verdulero tilda a Alí de "obstinado" y el entrenador lo moteja de "terco"; pero, ¿son justos tales calificativos? En rigor, Alí es empeñoso y perseverante antes que porfiado o tozudo. Asimismo, el padre le reprocha que se limite a "comer, jugar y dormir", y el inspector del colegio le recrimina por sus atrasos y considera "excusas" las justificaciones del niño. Empero, aunque los adultos no lo noten, Alí es honesto y mucho más responsable que cualquier niño de su edad. Algo similar cabría afirmar de Zahra. De hecho, los dos hermanos afrontan sensata y lealmente los problemas y muestran capacidad para improvisar argumentos (como cuando intercambian mensajes escritos o cuando Alí debe arrostrar las reprensiones del inspector). Así, pues, en estos niños la inteligencia está potenciada por una sensibilidad a flor de piel.

Ahora bien, dado que estos rasgos no se explican sólo por imitación de los modelos parentales ni por las enseñanzas escolares directas, cabría asumirlos como el resultado de un sistema de valores que atraviesa todo el sistema sociocultural. Pero, paradójicamente, los adultos integrantes de los sistemas familiar y escolar no perciben o no refuerzan -sobre todo al co- 
mienzo- estas notables cualidades infantiles, salvo cuando ya son muy evidentes.

2.6.- Religiosidad.- Por encima de lo que parecen ser valores familiares, asoma un fenómeno similar respecto de la divinidad: aunque la pobreza los afecta directamente, no impide que mantengan una profunda fe en Alá. Una vez más, eso parece correlativo al significado central que para el islamismo tiene la sumisión (en el sentido de humildad, no de autohumillación). Sin embargo, no se trata de una sumisión resultante de la imposición violenta y alienante; más bien cabe interpretarlo como un ethos profundamente interiorizado (al fin y al cabo, los islámicos hacen cinco oraciones diarias).

\section{Plano transubjetivo}

3.1.-Ética interiorizada.- La película muestra diversas actitudes que expresan valores relevantes y correlativos, tales como: $\left[1^{\circ}\right]$ lealtad en los vínculos antes que simple complicidad; $\left[2^{\circ}\right]$ honestidad (por ejemplo, aunque no tienen azúcar, el padre no concibe la posibilidad de consumir siquiera una cucharada de la abundante azúcar que se le encargó para efectos rituales); $\left[3^{\circ}\right]$ nobleza en las intenciones; $\left[4^{\circ}\right]$ abnegación de parte de todos, si bien resulta más conmovedora en niños tan pequeños.

3.2.-Esperanza y confianza.-Es notable con cuánta entereza arrostran los niños las adversidades. La esperanza y la confianza que muestran también parecen explicarse por una religiosidad interiorizada.

3.3.-Fraternidad versus competencia.- Mientras los demás niños participan en la competencia procurando un triunfo individual, Alí corre en pos del tercer lugar que le permitirá devolverle la alegría a su hermana; de hecho, va evocando los diálogos con ella, como si eso le inyectara energías adicionales.

3.4.-La pobreza como escuela de sencillez.- Tal como el padre -y probablemente la madre-, Alí y Zahra se han criado en el rigor y la escasez. De ahí que su sentido del esfuerzo y su pundonor sugieren más autosuperación que individualismo o exitismo.

3.5.-Maduración precoz.-De modo similar, la responsabilidad individual y el cumplimiento del deber no se explican meramente por un rigorismo impuesto o siquiera por el sentido de la disciplina, sino más bien por la comprensión precoz y profunda de las consecuencias ingratas que nuestros incumplimientos pueden tener para otros.

3.6.-Verticalidad y horizontalidad.- Pese al notorio verticalismo que impera tanto en la familia como en la escuela, se deja ver cuán beneficiosa resulta una cuota de horizontalidad para estimular la maduración de todos. Así, los progresos y la superación de los niños también contribuyen sutilmente a la superación de los mayores. Por ejemplo, cuando el padre no sabía cómo ofrecer persuasivamente sus servicios en el barrio acomodado 
-y balbuceaba azorado ante el citófono, que no le permitía ver el rostro del interlocutor-, la mayor desenvoltura de Alí lo complementa; asimismo, la perseverancia de Alí y su victoria en la carrera alegran al inspector que antes quiso suspenderlo de clases y al entrenador que en principio rehusaba inscribirlo (de modo que incluso cabría esperar que esas lecciones indirectas tengan efectos positivos en su desempeños como formadores).

\section{Plano ideológico}

4.1.-Desigualdad.-La desigualdad entre clases sociales es muy visible. La cámara muestra enormes diferencias entre el barrio acomodado de Teherán y el modesto sector en que vive esta familia. A eso se une además la desconfianza: las mansiones tienen perros guardianes hostiles, citófonos impersonales y cámaras de seguridad tan visibles que parecen decirle al visitante:-Recuerda que eres ajeno a este mundo. Por cierto, todo ello redunda en mayor distancia social e incluso segregación.

4.2.-Machismo.-Se observa cierto machismo, aunque sin el carácter explotador que suele darse en otros casos; por ejemplo, en la familia se asocia a la estructura patriarcal. Asimismo, la escuela mantiene la separación entre las niñas (que van a clases en las mañanas) y los niños (que asisten durante las tardes), y otro tanto ocurre con la mezquita. Incluso en la competencia deportiva no participan las niñas. Esta compartimentalización por género resulta paralela a la distinción por clase ya anotada.

4.3.-Diferencias intergeneracionales.- Matizando lo anterior, ciertas diferencias entre padres e hijos connotan un progreso intergeneracional. Por ejemplo, resulta muy sugerente la escena en que Karim no sabe qué responder y su hijo Alí improvisa una respuesta oportuna, ya que es por esa vía que el padre logra ganar un dinero jardineando; asimismo, pese a su corta edad, Zahra da la impresión de ser más autónoma y asertiva que su madre (bien que no menos hacendosa) ${ }^{2}$.

4.4.-Entre la precariedad y la dignificación del trabajo.-El padre no gana lo suficiente y por eso intenta obtener dinero extra; empero, no sabe cuánto cobrar por el jardineo e incluso inicialmente rechaza el pago, como si considerara ilegítimo hacerse pagar por un trabajo fácil o grato (lo vemos relajado y feliz mientras jardinea, y de hecho la música de fondo es casi infantil). También el trabajo se asocia entonces al sentido del deber antes que a imposiciones externas.

4.5.-Pobreza y honradez.-A lo largo de toda la película, la pobreza aparece connotada como digna. Y esa dignidad parece motivar la autosuperación.

4.6.-Comunitarismo.- El hogar de los protagonistas forma parte de un condominio. Pese a la pobreza compartida, allí prevalecen actitudes comunitarias, como cuando los niños llevan sopa a un matrimonio de ancianos. Asimismo, se ve estrechez y casi hacinamiento, pero no promiscuidad. 
Y es que la religiosidad induce solidaridad y respeto ya desde la crianza en el hogar, luego en la escuela y finalmente en la sociedad íntegra. ${ }^{3}$

\section{Plano simbólico}

5.1.-Zapatos.-Los zapatos cobran relieve desde el comienzo de la película hasta el final: primero vemos al zapatero remendando los zapatos de Zahra; asistimos luego a las peripecias de su pérdida y su búsqueda; sigue la tensión asociada al compartir las zapatillas de Alí (que se van transformado en chanclas); por último, sentimos el suspenso de la carrera y la incertidumbre de si obtendrá el premio de las zapatillas. Adicionalmente, se da un contraste entre los zapatos nuevos ofrecidos en la vidriera de una pequeña tienda -y también por televisión-y los viejos zapatos de ambos hermanos. Así, pues, el calzado es señal de status social, pero también connota protección del pie, vínculo permanente entre el hombre y el suelo (su "cable a tierra"). ${ }^{4}$

5.2.-El correr como metáfora de la vida. -El incesante correr sugiere metafóricamente que la vida implica dinamismo, metas y esfuerzo permanente. De hecho, Alí y toda su familia parecen un símbolo de la perseverancia.

5.3.-Agua. -El agua tiene también una presencia variada y emblemática (recordemos la fuente, la manguera, la lluvia, el estanque). Sus simbolismos parecen diversos, pero en un medio desértico se asocia claramente a un bien preciado y, además, tiene connotaciones sociales (por ejemplo, el té se bebe junto a otros) y también espirituales (el agua purifica). En el caso del agua turbia (como la acequia donde a Zahra se le cae una zapatilla), el simbolismo se invierte y se asocia a peligro.

5.4.-Bicicleta.-La bicicleta del padre también resulta simbólica: contrastada con los vehículos motorizados, connota precariedad (de hecho termina averiada cuando chocan); a la inversa, sise la contrasta con andar a pie, sugiere también cierta autonomía, esfuerzo y autosuperación, valores que la película transmite de principio a fin. Curiosamente, el padre y Alí caen desde la bicicleta justamente mientras el padre fantasea respecto de cuánto podrían llegar a ganar como jardineros ocasionales. Es decir, parece otro "cable a tierra".

5.5.-Lápiz.-El lápiz aporta su propio simbolismo: constituye el premio al esfuerzo de Alí en los estudios, pero luego será un regalo compensatorio de éste a Zahra. A su vez, cuando ella lo pierde y lo recoge la misma niña que había recibido los zapatos de Zahra, uno supone que se lo quedará; sin embargo, la busca para devolvérselo y finalmente lo hace. Es decir, este sencillo objeto connotaría la autosuperación individual, pero también la honesta vinculación interpersonal en torno a la justicia: es justo y noble premiar el esfuerzo de un buen alumno; no es menos justo ni menos noble compensar el sacrificio y la lealtad de una hermana, y es claramente justo y noble devolver lo que parece sin dueño, si es que se puede averiguar a 
quién pertenece (por cierto, esto último cobra mayor relieve considerando la precariedad económica de la niña que hace tal gesto).

5.6.-Pececillos.-Para los occidentales, los peces remiten a Cristo (ya que eligió como discípulos a simples pescadores), pero en el filme reclaman una interpretación menos codificada. Para empezar, aparecen tres veces, y siempre en momentos gratos. En principio sugieren inocencia, cierta generosidad y una valoración de la vida (pues, pese a su pobreza, la familia se las arregla para alimentarlos); finalmente, también connotan la mansedumbre de Alí, ya que los pececillos nadan muy cerca de él y hasta lo rozan confiadamente, como si lo premiaran con una sesión gratuita de ictioterapia.

5.7.-Alimentos.- El té y el azúcar aparecen asociados más bien al espíritu antes que a la necesidad meramente corporal; de hecho, son alimentos sutiles. Por otra parte, la sopa que la madre le envía a la vecina connota mucha solidaridad, ya que, en una condición tan precaria, ella bien podría no compartir el escaso alimento. A su turno, el anciano retribuye con un puñado de semillas comestibles que mantenía bajo la cama. Una vez más, vemos prevalecer reciprocidad por encima de la pobreza.

5.8.- Pompas de jabón.- Cuando los hermanos lavan las zapatillas, juegan a formar pompas de jabón. Este simbolismo sugiere tanto el vuelo de la fantasía como la transparencia y la vulnerabilidad de la niñez.

5.9.- Nombre y destino.- Llamarse Alí en una sociedad chiíta marca el carácter del protagonista: recordemos que los chí́tas -o shihitas- no siguieron a los califas sucesores de Mahoma, sino al primo y yerno de Mahoma, cuyo nombre era precisamente Alí (Stangrom, 2009, pp. 46-47). Asimismo, para la hermana llamarse Zahra supone también una directriz, pues fue el otro nombre con que se conoció a Fátima, hija del profeta Muhammad Ibn Abdullah. Además, la etimología árabe de 'Zahra' remite tanto a blancura inmaculada como a flor luminosa. Ambos ejemplos muestran entonces cómo la cultura tradicional penetra en la formación de la personalidad.

\section{Plano estético}

6.1.-Condensación.- Se cuenta bien y brevemente una historia (la película no llega a la hora y media), pero esa historia ilumina indirectamente el contexto sociocultural y religioso. Mediante símbolos sutiles y variados connotadores, el filme logra una notable sinergia entre elementos opuestos: una trama sencilla, pero un mensaje profundo; una historia de niños inocentes y en parte adultizados; una fuerte "carga" espiritual y a la vez una gran fluidez narrativa.

6.2.-Progresión.-Muy relacionado con lo anterior, destaca un notable manejo del suspenso. El acompañamiento musical es también significativo, pues constituye casi un lenguaje paralelo, en estrecha correlación con el suspenso. 
6.3.- Clasicismo de la forma.- Se trata de una narración "clásica”, que sigue el orden "natural": inicio, surgimiento de un conflicto, intensificación del mismo y desenlace. Esto parece correlativo al relieve de la tradición religiosa iraní, que contrasta con la “modernización” del país.

6.4.- Narración visual.- La cámara narra con eficacia y sutileza, alternando primeros planos y tomas panorámicas, como si articulara lo individual y lo colectivo.

6.5.- Actuación.- La actuación es muy convincente de parte de todos los actores, si bien sobresalen los dos niños protagonistas.

6.6.-Paralelismos, contrastes y armonía global.-El filme logra un fino equilibrio entre elementos análogos y al mismo tiempo contrapuestos. Por ejemplo, Alí y Zahra contrastan por el género, pero su condición de niños los asemeja y a la vez los distingue del mundo adulto. Aparte de la edad y el género, también se aprecia un claro contraste entre las clases sociales. Por otra parte, Alí formula voluntariamente dos promesas incompatibles. Asimismo, hay otros contrastes; por ejemplo, Alí llega atrasado a la escuela, pero la camioneta del colegio también llega tarde a la competencia, y en este caso la responsabilidad era del inspector y del entrenador, los mismos que antes habían sido severos con él por sus retrasos (en llegar a clases y en inscribirse en la carrera de preselección). También contrastan los zapatos y pies (que tocan la tierra) con la espiritualidad que tiende al cielo. E incluso hay un contraste casi subliminal entre el azúcar y la sal que vocea un vendedor callejero.

\section{Articulación entre planos y niveles}

1.- Articulación y globalidad.-El análisis precedente ha distinguido explícitamente seis dimensiones y, más implícitamente, varios niveles de exploración. Por cierto, tales dimensiones y niveles están articulados en el todo como en una síntesis. Por ejemplo, en el plano intrasubjetivo se hizo notar la incompatibilidad de las dos promesas de Alí como un factor de tensión "subjetiva"; no obstante, es obvio que dichas promesas se dieron en un plano intersubjetivo y que, por lo mismo, no debemos disociarlas de tal contexto. En efecto, el dilema 'intrapersonal' de Alí tiene motivos e implicaciones 'interpersonales' (si Alí llega tercero podrá cumplir lo prometido a la hermana, pero decepcionará al entrenador; inversamente, si llega primero, alegrará al entrenador, pero entristecerá a la hermana), y aun 'transpersonales' (cumpliendo su deber, un islámico cumple con Alá ${ }^{5}$ ).

2.- Automonitoreo y metacognición.-Por otra parte, cada uno de los seis planos (intersubjetivo, intrasubjetivo, transubjetivo, ideológico, simbólico y estético) se presta para comentarios de muy distinto rango. Por de pronto, cabe distinguir seis niveles de análisis, desde el más sencillo hasta el más complejo y exigente: descripción, inferencia, interpretación, valoración, introspección e imaginación creativa. Se explicará entonces tal jerar- 
quía como una manera de propiciar el automonitoreo y la metacognición. Por ejemplo: $\left[1^{\circ}\right]$ este comentario comienza en un nivel descriptivo (mostrando el contraste entre las dos promesas); $\left[2^{\circ}\right]$ pasamos luego a un nivel inferencial (al colegir que el niño experimenta tensión por no poder cumplir simultáneamente ambas promesas); $\left[3^{\circ}\right]$ avanzamos después hasta el nivel interpretativo al postular que tal tensión connota cuán estrictas son las normas de crianza y de socialización; $\left[4^{\circ}\right]$ por último, llegamos al nivel valorativo al destacar como artísticamente logrados esos y otros connotadores fílmicos, ya que es propio del arte sugerir y no adoctrinar (aunque se trate de actitudes o virtudes tan deseables como el compromiso, la fraternidad y la solidaridad). Si luego recordamos que hay aún dos grados más profundos de apropiación del filme (o de un texto cualquiera), podemos intentar nuevos avances; por ejemplo, $\left[5^{\circ}\right]$ pasaremos a un nivel introspectivo si cada uno se ausculta a sí mismo para descubrir qué reacciones emocionales le provocaron determinados personajes o ciertas escenas, con quiénes se identificó más, a quiénes rechazó, etcétera; por último, [6 alcanzaremos el nivel creativo si, a propósito de la película, procuramos activamente imaginar desarrollos o desenlaces alternativos o incluso reflexiones más generales.

3.- Comprender para aprender mejor.-Por cierto, distinguir planos de exploración y nivelesde comprensión no implica separarlos unos de otros, pues ello constituiría una violencia contra la obra de arte. Así, por ejemplo, la riqueza del plano simbólico se correlaciona con la riqueza del plano estético, del mismo modo en que las dimensiones intrapersonal y transpersonal guardan relación directa con la dimensión interpersonal. En consecuencia, confirmamos una vez más que el ejercicio de analizar tiene sentido si logramos distinguir sin separar (ni mucho menos disociar) los planos o dimensiones. Es más: un buen análisis debería culminar en una síntesis superior.

\section{Ejemplificación retrospectiva de los seis niveles}

Para interiorizar mejor la jerarquía de seis niveles de comprensión, convendrá dar una mirada retrospectiva y distinguir metacognitivamente los pasos dados. ${ }^{6}$

1) Nivel descriptivo.- En primera instancia, este nivel se alcanza observando con atención la película para captar la trama y luego ofrecer una sinopsis clara. Por cierto, así como podemos observar con mayor o menor perspicacia, también nuestras descripciones pueden alcanzar distintos niveles de profundidad. Con todo, acá nos bastará entender la descripción como un nivel preliminar de análisis, cuya relevancia radica en prepararnos para hacer luego inferencias pertinentes y relevantes. Así, aunque es en la sinopsis donde más descriptivos debemos ser (consignando los hechos relevantes sin introducir interpretaciones ni valoraciones), el nivel descriptivo no se limita a resumir la trama; de hecho, en cada dimensión serán necesarias nuevas descripciones para introducir o justificar comentarios inferenciales, interpretativos o valorativos (de otro modo, tales comenta- 
rios parecerían infundados). Por ejemplo, al observar que ciertas conductas y actitudes se reiteran en tales o cuales personajes, inferiremos algunos rasgos de carácter; al captar determinados fenómenos, podemos conjeturar sus causas o prever sus implicancias; percibiendo cierto vacío en la secuencia de escenas, colegiremos que algo ocurrió, aunque las imágenes no lo hayan mostrado.

2) El nivel inferencial.- Como se ve, este segundo nivel está indisolublemente ligado al primero, ya que presupone fundarse en lo observable para colegir lo inobservado, pero seguro o muy probable. En otras palabras, dado que el filme no puede mostrar todo, forzosamente deja muchos elementos y mensajes implícitos. Veamos algunos ejemplos:[1] A partir del precio de las papas (30 tomens) y del precio que cancela otro cliente (65 tomens), cabría dimensionar comparativamente qué tan caros son los zapatos exhibidos en la vitrina; asimismo, cuando nos enteramos del monto recibido por el trabajo ocasional, podemos luego inferir qué tan difícil será comprar los zapatos nuevos a Zahra. [2 ${ }^{\circ}$ Si notamos la aparente incongruencia de que el padre pida azúcar para su té mientras está precisamente moliendo azúcar para las ceremonias de la mezquita, podemos entender que eso revela un profundo respeto por lo ajeno, que él no se apropia ni siquiera

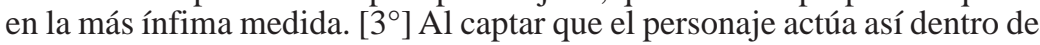
la casa (de hecho, le explica a la hija que él no puede consumir ni siquiera un terrón de esa azúcar que le fuera confiada), concluimos que tal rigor constituye una norma de crianza, conclusión que hasta cierto punto confirmamos al ver que los niños presentan una ética tan interiorizada y sin fisuras, pues ello es propio de quien aprende a partir de buenos modelos (en este caso,

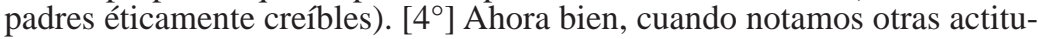
des similares de parte de otros personajes, hacemos una inferencia de mayor alcance, pues ya estamos autorizados para asumir que probablemente se trata de un patrón sociocultural y no sólo de un rasgo caracterial o una norma familiar. [5 ${ }^{\circ}$ ] Aunque la carrera es larga y el día es soleado, todos los niños corren con pantalones deportivos largos; por tanto, estamos autorizados a inferir que probablemente ahí opera alguna norma cultural, moral o religiosa. $\left[6^{\circ}\right.$ ] En cambio, cuando percibimos que el carretonero toma los zapatos y luego los tapa, sólo podemos conjeturar que sabía que estaba llevándose algo más que los desechos habituales; sin embargo, tal pensamiento no es una inferencia segura o muy probable, aunque sí podría transformarse -con la fundamentación pertinente- en una hipótesis plausible, que como tal trasciende el plano inferencial y nos lleva al nivel siguiente.

3) El nivel interpretativo.- Este tercer nivel supone ir más allá de las inferencias, en el entendido de que ellas suelen ser insuficientes para comprender fenómenos complejos, difusos o ambiguos. Por tanto, interpretar requiere ser consciente del riesgo de errar, puesto que las conjeturas, las hipótesis y las abducciones son por fuerza más inciertas que las deducciones y las inducciones. En términos generales, la mayor parte de los símbolos requiere interpretaciones, pues su sentido profundo no es deducible como la incógnita de una ecuación, y ni siquiera cabe esperar que un diccionario de símbolos - aun si se trata de uno tan bueno como el dirigido por 
Chevalier ${ }^{7}$ - nos dispense de la tarea hermenéutica. Desde luego, aparte del plano simbólico, los otros cinco planos invitan de continuo a formular interpretaciones. Con todo, por muy fundadas que éstas sean, siempre asomará el espectro de la incertidumbre. Por ejemplo, dado que el filme no da pistas precisas para inferir qué aqueja a la madre, podríamos preguntarnos si se trata de un cuarto embarazo; sin embargo, no cabe descartar otras hipótesis. Recordemos que estamos frente a una obra de arte, no ante un problema de lógica deductiva o un acertijo, y que por tanto haríamos bien en adoptar el procedimiento de las hipótesis múltiples, estimulando así el pensamiento divergente y la creatividad abductiva de los estudiantes.

4) El nivel valorativo. Al apreciar cualquier arte, se suele valorar la obra como totalidad y/o dar relieve a algunos aspectos de ella.En cualquier caso, no es realista proponerse como meta una presunta "apreciación neutral”, que por lo demás envolvería una contradictio in terminis. Por cierto, los excesos impresionísticos hacen deseable contener el subjetivismo para fundamentar las interpretaciones de modo intersubjetivamente razonable; no obstante, aspirar a la "imparcialidad valorativa" es tan iluso como pretender una "interpretación objetiva", pues la actitud de no juzgar no puede sostenerse indefinidamente. Además, así como sería erróneo suponer que sólo el plano simbólico requiere interpretaciones, resultaría también disparatado creer que el nivel valorativo remite sólo al plano estético. Incluso cabría afirmar que desentenderse de valorar reduce el goce artístico. En cualquier caso, en las páginas precedentes no se vaciló en formular juicios valorativos a propósito de ciertas costumbres, tendencias y actitudes observables en el film. Al fin y al cabo, la obra de arte se dirige precisamente a nuestro ser íntegro, sin escisiones artificiales.

Por supuesto, lo anterior tampoco nos autoriza para ser arbitrarios ni rígidos al valorar; de hecho, resulta preferible emitir juicios únicamente después de haber alcanzado al menos los tres primeros niveles de apreciación (descripción, inferencia, interpretación).Por lo demás, si extrapolamos esa precaución al plano interpersonal, estaremos fomentando mejores hábitos interaccionales y contribuyendo a formar personas más responsables y prudentes a la hora de emitir juicios, lo que redundará en mayor civismo.

5) El nivel introspectivo.- Puesto que una buena película nos toca sutil, variada y profundamente, es natural que induzca en nosotros más de una introspección. Después de todo, interpelándonos como seres completos, suscita nuestros entusiasmos, dudas y resistencias, y de paso desafía nuestros prejuicios, creencias y valores. Al volver la mirada hacia sí mismo, cada espectador puede entonces preguntarse si lo que cree ver está realmente en la obra o es más bien una proyección de su subjetividad. En el caso concreto de Niños del cielo, las dinámicas familiares pueden evocar a cada espectador escenas personales. Uno podría examinar entonces la propia biografía para ver si en las relaciones de uno con sus propios hermanos o familiares hay tanta lealtad y cooperación como entre los personajes de esta película. En fin, las introspecciones son personales e íntimas, así que lo anterior cuenta como simple ejemplificación. 
6) El nivel heurístico o creativo.- La apreciación concienzuda de la película (distinguiendo varios planos y niveles) estimula nuestra imaginación y nuestra reflexión; asimismo, ciertos niveles de desafío fomentan mejores aprendizajes. Y si grandes creadores se inspiran en obras preexistentes, ¿cómo no reconocer que una gran película es también un modelo condensado de imaginación y lucidez, de intuición y pensamiento, de sensibilidad y de valores, de talentos individuales y grupales? Así, pues, el buen cine equivale a una invitación para ejercitar el pensamiento divergente.

Pero ¿de qué modo se puede ejercitar y ejercer la creatividad? [1ㅜ] En primera instancia, uno puede representarse otros desarrollos, otros finales, otras acciones, otros personajes, otras perspectivas. Por ejemplo, si tuviéramos que adaptar esta historia a nuestro país, ¿cómo se desarrollaría la historia? Y si uno adopta la perspectiva de una cineasta feminista, ¿cómo cambiarían el guión, las tomas y la dirección? Puestos a imaginar una segunda parte de esta película, ¿qué ocurriría en ella?[2 En un nivel de mayor apropiación del método propuesto, los alumnos pueden transferir hacia la vida cotidiana sus progresos en perspicacia, razonamiento y creatividad; de hecho, sería antinatural ejercitar tales facultades sólo en la apreciación fílmica, desentendiéndose de la exis-

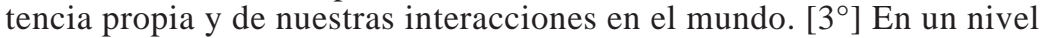
superior, la apreciación cinematográfica compartida puede estimular a algunos estudiantes a escribir ensayos de mayor alcance, que valgan como reflexiones autónomas y no exclusivamente como comentarios de la película. ¿Cuántas reflexiones profundas se han escrito a partir de El Quijote o Hamlet, pero sin limitarse a comentar tales obras? ¿Cuánta buena filosofía se ha hecho de cara a un cuadro o a otra clase de obras artísticas?

Así aplicada, la inteligencia creadora podrá algunas veces conducirnos muy lejos de la obra admirada, allí donde comienza propiamente la originalidad. Al fin y al cabo, como dijo Gaudí, la originalidad es también lealtad a los orígenes. En cualquier caso, lo relevante es que, si asumimos la película como un "texto" audiovisual, comprenderemos que todo texto tiene asociado un intertexto, y que la intertextualidad activa y consciente es práctica común entre los creadores. En este caso, un intertexto pertinente lo aportan las demás obras del propio director; entre ellas, cabe destacar especialmente El color del paraíso (1999), tan admirable como la que acá se analiza y que también tiene relevancia socioeducacional. Y si bien no desarrollaremos aquí esa intertextualidad, destaquemos siquiera que los finales de ambos filmes combinan tristeza y esperanza mediante claves casi imperceptibles: en Niños del cielo, vemos que en la parrilla de la bicicleta el padre lleva zapatos nuevos para ambos hijos; en El color del paraíso, el niño ciego mueve sutilmente los dedos, lo que sugiere que aún está vivo y que eventualmente podrá recuperarse de lo que parecía una muerte segura. 


\section{VI.- Reflexión psicoeducacional y socioeducativa}

1) Progresiones articuladas.-El presente escrito ofrece una apreciación ordenada de una película, análisis que sería el equivalente a lo que en literatura y humanidades se conoce como un comentario de texto y también como lectura atenta (close reading). Asimismo, resultó productivo introducir en la apreciación fílmica la distinción de niveles de comprensión que se aplica a propósito de la lectura de textos, jerarquía que he seguido más o menos de cerca (si bien he agregado la introspección como penúltimo nivel). Por cierto, hace ya muchos siglos los primeros padres de la iglesia distinguían dos, tres y aun cuatro niveles de significación de los textos bíblicos: literal, alegórico (figurado), moral y anagógico (o espiritual). ${ }^{8}$

Sea que debamos evaluar la comprensión lectora o la agudeza en apreciación literaria o textual, surge naturalmente una espiral de niveles progresivamente más complejos. En tal sentido, el modelo estructural del intelecto propuesto por Guilford ([1967] 1977) también postula una jerarquía implícita de los productos intelectuales, los que van desde las simples unidades y las clases, pasando luego a las relaciones interclases y los sistemas, para terminar con las transformaciones y las implicaciones.

2) Compatibilidad con otros modelos jerárquicos.-En el ámbito psicoeducativo, la apreciación fílmica aquí propuesta también es compatible con otros modelos jerárquicos, como el desarrollado por Piaget para el desarrollo cognitivo y el propuesto por Kohlberg a propósito del desarrollo moral. De hecho, siempre es posible mediar un enriquecimiento de la comprensión fomentando el pensamiento formal y el discernimiento moral. La clave está en progresar desde el pensamiento concreto hacia otro más abstracto, y desde una moral preconvencional o convencional hacia una postconvencional. En ambos casos, el docente debe mostrar el mayor alcance de las operaciones lógicas y de los criterios derivados de principios demostrables o al menos susceptibles de justificación argumentada.

3) Metacognición y pensamiento crítico-- La apreciación psicofílmica aquí propuesta produce mejores efectos al propiciar un incremento de la conciencia metacognitiva. La idea es que estudiantes y educadores descubramos nuestros sesgos perceptuales, nuestros prejuicios cognitivos, nuestros razonamientos falaces y nuestras actitudes erróneas. Al mismo tiempo, el docente debe propiciar que los alumnos valoren sus aciertos, potencien sus habilidades argumentativas, profundicen su escucha y afinen su pensamiento crítico.

4) Lenguaje, pensamiento e interacción.- Todo lo anterior presupone estimular en los alumnos una mayor conciencia acerca de los alcances del lenguaje en el pensamiento y en la convivencia. Por ejemplo, muchos estudiantes padecen graves limitaciones en su vocabulario activo, de modo que a duras penas consiguen expresar una parte de los comentarios u observaciones que quisieran compartir. Si eso ya determina la calidad de las descripciones -que requieren introducir matices más o menos precisos en 
la caracterización de los personajes o en la calificación de sus conductas observables-, resulta mucho más decisivo para defender una interpretación que uno estima razonable, pero que además debe parecerlo a otros. Es decir, no se trata sólo de incentivar la dimensión cognitiva o metacognitiva del aprendizaje, sino también las "externalidades" en el plano interpersonal e incluso cívico, puesto que una sociedad se beneficia cuando sus integrantes piensan y dialogan de modo más nítido y constructivo, aprendiendo unos de otros ${ }^{9}$. Eso requiere argumentar para convencer, no para apabullar o lucirse.

5) Circularidad virtuosa entre los aprendizajes cooperativo y colaborativo.-Como se consignó en nota 4 , no es raro que la perspicacia de los estudiantes termine enriqueciendo la comprensión del propio docente. Pondré otros dos ejemplos.[1 $1^{\circ}$ ] Cierta alumna del seminario de Psicología, cine y comprensión (UDP 2009) ${ }^{10}$, hizo notar que el padre actuó con negligencia al no revisar previamente los frenos de la bicicleta, porque puso en riesgo a su hijo. Por mi parte, no había reparado en eso, al parecer porque a los hombres se nos escapan los aspectos asociados convencionalmente al rol materno. $\left[2^{\circ}\right]$ Muy recientemente, mi ayudante ${ }^{11}$ me hizo notar que en esta película resulta muy simbólico que el agua casi siempre refleja el cielo.

Consigno estos hechos como un argumento más a favor de articular los aprendizaje cooperativo y colaborativo, pues ello propicia que los estudiantes profundicen su comprensión aprendiendo unos de otros, y también que el docente interiorice su quehacer como un proceso de profundización continua. Mientras más aprendan los alumnos, más capaces serán de estimular la comprensión del propio profesor, quien debería explicitar cada vez que alguien aporte un comentario o argumento pertinente que él no había concebido. Por cierto, esto motivará a los estudiantes y redundará en un círculo virtuoso de retroalimentación mutua y continua. A falta de puentes entre alumnos y docentes y entre una generación y otra, el aprendizaje cooperativo y colaborativo en torno al cine nos reaviva la esperanza de una creciente democratización de la sala de clases.

6) Del pensamiento crítico al sociocrítico.-La película permite preguntarse qué tan apropiadas son las exigencias que afrontan los niños iraníes. Por ejemplo, una carrera de cinco mil metros parece excesiva para niños tan pequeños como Alí, con mayor razón si el recorrido incluye subidas y bajadas. Asimismo, se puede observar que, pese a su corta edad, Zahra tiene un buen rendimiento en materia de lectoescritura (se la ve escribiendo fluidamente en persa), y en otra escena afronta con soltura los ejercicios de fracciones de una prueba de aritmética. Ahora bien, ¿ंson exigencias desproporcionadas para alumnos de esa edad o, al revés, los occidentales subestimamos las potencialidades de los niños? La discusión queda abierta.

Asimismo, un docente aprovechará de estimular la curiosidad intelectual de los estudiantes, sugiriéndoles recabar información objetiva sobre Irán y la revolución política y religiosa desarrollada a partir de 1979. Así 
podrían sorprenderse averiguando queluego del triunfo de la Revolución Islámica, y tras superar una guerra de ocho años, Irán se ubica hoy entre los primeros diez países del mundo en desarrollo industrial, educativo, de producción científica y manejo de recursos naturales. De hecho, sus avances en educación e investigación son once veces mayores que en el resto del mundo, y casi dos tercios de los estudiantes universitarios son mujeres. ${ }^{12}$

Pasando entonces a un nivel sociocrítico, cabe cuestionar con qué fundamento se confunde el respetable Islam con fundamentalismo islámico, reducción que lleva aparejada otra: el fundamentalismo aparece como sinónimo de terrorismo. ¿Son estos estereotipos fenómenos casuales o están políticamente inducidos? ${ }^{13}$

Finalmente, también es relevante preguntarse hasta qué punto nuestra ignorancia respecto a otras culturas o religiones es el origen de nuestros prejuicios y conflictos bélicos. Sin ir más lejos, el informe de pares sobre este mismo artículo me hizo notar la relevancia de distinguir -al interior del islamismo- entre la mayoría sunita y la minoría chiíta, matiz que yo había pasado por alto.

\section{Conclusión}

Como se ve, aun sin ser exhaustivo, el análisis precedente demuestra que una buena película es inagotable, y que su apreciación ofrece múltiples y estupendas ocasiones para promover el descubrimiento, la metacognición, el aprendizaje cooperativo y el metaaprendizaje. La práctica resuelve la mayor parte de las dificultades que este artículo deja insinuados. 


\section{Notas}

${ }^{1}$ El autor ha proyectado esta película ante numerosos estudiantes de pregrado y postgrado de psicología y educación. En las notas 4, 10 y 11 se alude a algunos comentarios de esos alumnos.

${ }^{2}$ Si creemos a Axworthy (2010, p. 324), esto sería un fenómeno de amplio alcance: “El éxito de las mujeres iraníes en la educación y su mayor peso específico en el ámbito laboral y en la economía representan un cambio social y cultural muy importante. No cabe duda de que, a su debido tiempo, junto con otros factores, este cambio tendrá profundas consecuencias para la sociedad en su conjunto [...]”

${ }^{3}$ Según el Islam, la autoridad paterna viene de Alá. Por ejemplo, Seyyed Hossein Nassr (citado por Mires, 2005: 130) expresa: "La familia islámica es una representación en miniatura de la sociedad musulmana. En ella actúa el hombre, o el padre, de acuerdo con la naturaleza patriarcal del Islam [...]”.

${ }^{4}$ En el Seminario Psicología, cine y comprensión (UDP 2009), Francisca Roa Cid hizo notar la sutil oposición entre los zapatos, que ligan a los protagonistas a la tierra, y el título del film, que los remite al cielo.

${ }^{5}$ Aunque el derecho musulmán distingue entre el deber individual (fard 'ayn) y el colectivo (fard kifaya), cada persona aprende desde pequeña que ambos son indisociables de la religiosidad genuina. Ver Felipe Maillo Salgado: Vocabulario de historia árabe e islámica. Akal, Madrid, ${ }^{2} 1999$ [ $\left.{ }^{1} 1996\right]$ p. 82. Respecto al Islam, consigno en orden meramente alfabético otros diccionarios: [1] Chebel, Malek: Diccionario del amante del Islam. Paidós Ibérica, Barcelona, 2005 [París, 2003], 462 pp. [2] El Mushtawi, Sami Abdel Mordi: Breve diccionario de terminología islámica.Editorial Dunken, Buenos Aires, 2005, 120 pp.[3] Ginsberg, Terri; Chris Lippard, Chris: Historical Dictionary of Middle Eastern Cinema. Scare Crew Press, Maryland, 2010, p. 259.[4] Gómez García, Luz: Diccionario del Islam y el islamismo. Espasa, 2009, 412 pp.[5] Guidère, Mathieu: Historical Dictionary of Islamic Fundamentalism. Scare Crew Press, Maryland, 2012, 504 pp.[6] Gilliot, Claude; Meunier, Roger; Ordóñez Villarroel, Manuel: Diccionario del Islam. Religión y cultura. Editorial Monte Carmelo, Burgos, 2006, 834 pp. [7] Sfeir, Antoine (ed.): The Columbia World Dictionary of Islamism. Columbia University Press, N. York, 2007 [París, 2002], 430 pp.

${ }^{6}$ Adicionalmente, también se puede ver una explicación de los seis niveles en Llanos 2009 y Llanos 2010.

${ }^{7}$ Chevalier, Jean (dir); Gheerbrant, Alain (col): Diccionario de símbolos. Editorial Herder, Barcelona, 1991 [París, 1969], 1.107 pp.

8 "Por ejemplo, el sistema cuádruple atribuye cuatro niveles de significado a la ciudad de Jerusalén: (1) literal: la ciudad israelita/jebusea; (2) alegórico: la iglesia de Cristo; (3) moral: el alma de las personas; y (4) anagógico: la ciudad celestial de Dios”. Scott Duvall y Daniel Hays, 2008: 256.

${ }^{9}$ Destaco aquí sobre todo el aporte de Wertsch (1998).

${ }^{10}$ Se trata de Mónica Benavides Sánchez. 
${ }^{11}$ Manuel Araneda Labra.

${ }^{12}$ Ver Akbar Esmaeil Pour: Logros de La Revolución Islámica: 32 años después de su victoria. 2010. Disponible en http://www.ipis.ir/pdf/politicaexterior/4.pdf

${ }^{13}$ Para introducirse a la compleja historia de Irán, ver John Henry Lorentz: Historical dictionary of Iran. Scarecrow Press, Inc., 2007, 479 pp. 


\section{Bibliografía}

Axworthy, Michael (2010), Irán. Una historia desde Zoroastro hasta hoy. Turner Publicaciones, Madrid [Londres, 2007],382pp.

Guilford, J. P. (1977), La naturaleza de la inteligencia humana. Editorial Paidós, Buenos Aires [N. York, 1967], 589 pp.

Llanos, Eduardo (2009), “Análisis pragmático integral de un microcuento de Borges”. Estudios Filológicos, Valdivia, No 44, 2009, pp. 107-121, <http:/ /www.scielo.cl/scielo.php?pid=S0071-17132009000100007 \&script=sci_arttext>

Idem (2002; 2010), “Para un análisis psicocinmatográfico integral”. Mesa redonda, Universidad Central, Santiago, $\mathrm{N}^{0}$ 1, pp. 137-150. Levemente corregido, el artículo apareció también en Gaceta de Psiquiatría Universitaria. 2010, Año 6, $N^{\circ}$ 4, pp. 492-500. Disponible on line.

Idem (2010), “¿A quién ama Gilbert Grape?”, Gaceta de Psiquiatría Universitaria. 2010, Año 6, No 3, pp. 351-363. <http://revistagpu.cl/2010/ Septiembre/GPU\%2020103\%20(PDF)/ANA\%20A\%20quien\%20ama\% 20Gilbert\%20Grape.pdf>

Mires, Fernando (2005), El islamismo: la última guerra mundial. Editorial Lom, Santiago, 297 pp.

Scott Duvall, J.; Daniel Hays, J. (2008), Hermenéutica. Entendiendo la Palabra de Dios. Clie, Barcelona [Miami, 2001], 600 pp.

Stangrom, Jeremy, Religión. Pequeñas grandes ideas. Oniro, Barcelona, 2009 [Londres, 2007], 128 pp.

Wertsch, James V., La mente en acción. Aique, Buenos Aires, 1999 [1998], 304 pp.

Recibido: 25.12.2012

Aceptado: 30.04.2013 